\title{
ANALISIS EFISIENSI USAHATANI PADI SAWAH: KASUS PADA PETANI PENGGUNA HANDTRAKTOR DI KELURAHAN KEMUMU, KECAMATAN ARGAMAKMUR, KABUPATEN BENGKULU UTARA
}

\author{
EFFICIENCY ANALYSIS OF PADDY FARMING: CASE STUDY OF \\ FARMERS USING HANDTRACTOR IN KEMUMU VILLAGE, \\ SUBDISTRICT OF ARGA MAKMUR, DISTRICT OF NORTH BENGKULU
}

\author{
Harry Tsaputra, Bambang Sumantri, dan Agus Purwoko \\ Jurusan Sosial Ekonomi Pertanian, Fakultas Pertanian, Universitas Bengkulu
}

\begin{abstract}
The objective of this study is to analyze the efficiency and risk of rice farming with and without hand tractor. Sixty six respondents are selected using simple random sampling. $R / C$ ratio is used to estimate farm efficiency and business risk analysis as suggested by Kadarsan (1995) is used to examine risk that is probably faced by farmers. The results showed that farmers used tractors is more efficient than others. This conclusion is based on average $R / C$ ratio of 3.02 and 2.69 for farmers with and without tractor respectively. Statistic $t$ test also support the existence of economic efficiency dissimilarity.
\end{abstract}

Keyword: Efficiency, Business Risks, Rice Farming

\section{PENDAHULUAN}

Pembangunan sektor pertanian utamanya bertujuan untuk meningkatkan produksi pangan guna memenuhi kebutuhan penduduk. Peningkatan produksi pangan dilakukan secara intensifikasi, salah satunya dengan cara melakukan pengolahan lahan secara tepat. Pengunaan alat mesin pertanian, khususnya Hand Tractor, adalah salah satu upaya petani dalam melakukan efisiensi usahatani melalui penghematan biaya dan waktu pengolahan lahan.

Data yang dipublikasikan oleh Badan Pusat Statistik (2010) menginformasikan bahwa ditinjau dari luas panen dan jumlah produksi, Kabupaten Bengkulu Utara dapat dikatakan sebagai sentra produksi padi. Luas panen padi di Kabupaten ini mencapai 21.620 ha atau $16,26 \%$ dari total luas panen padi Provinsi Bengkulu dengan produksi sebesar 83.064 ton atau $16,28 \%$ total produksi provinsi. Salah satu wilayah sentra produksi padi di Kabupaten Bengkulu Utara adalah Kecamatan Argamakmur, khususnya di 
Kelurahan Kemumu. Desa ini memiliki jumlah populasi petani padi terbanyak yang mencapai 386 orang yang terbagi dalam 12 kelompok tani dengan luas lahan $368 \mathrm{Ha}$.

Pengalokasian penggunaan faktor produksi efektif dan efisien akan dapat menghasilkan produksi yang maksimal. Dengan produksi yang maksimal, maka pendapatan yang dihasilkan usahatani juga akan meningkat. Namun demikian, setiap petani selalu dihadapkan pada resiko dalam melaksanakan usahataninya, termasuk penggunaan traktor untuk pengolahan lahan usahatani padi. Salah satunya adalah apakah penggunaan traktor akan dapat mengefisienkan biaya yang dikeluarkan oleh petani dimana pada gilirannya akan mempengaruhi pendapatan yang diterima oleh petani. Berangkat dari permasalahannya ini, penelitian ini bertujuan untuk mengetahui tingkat efisiensi pada usahatani padi sawah dengan dan tanpa menggunakan Hand Traktor di Kelurahan Kemumu.

\section{METODE PENELITIAN}

Penelitian ini dilakukan di Kelurahan Kemumu Kecamatan Argamakmur, Kabupaten Bengkulu Utara dengan pertimbangan bahwa masyarakatnya sebagian besar bermata pencaharian sebagai petani padi yang menggunakan traktor dan ternak sebagai alat pengolah lahan pertanian. Responden dalam penelitian ini adalah 44 petani yang menggunakan hand traktor dan 22 petani tanpa menggunakan hand traktor dipilih dengan sampling acak sederhana (Simple Random Sampling).

Metode analisis data yang digunakan adalah analisa efisiensi usaha meruapakan perbandingan penerimaan dan biaya (Soekartawi, 1995)

$$
R / C \text { rasio }=\frac{\text { TotalPenerimaan }}{\text { TotalBiaya }}=\frac{T R}{T C}
$$

dengan kriteria, jika $R / C>1$, maka usahatani efisien, $R / C<1$, maka usahatani tidak efisien, dan $\mathrm{R} / \mathrm{C}=1$, maka usahatani impas/belum efisien. Selanjutnya, dilakukan uji $\mathrm{t}$ beda rata - rata untuk mengidentifikasi perbedaan tingkat efisiensi.

\section{HASIL DAN PEMBAHASAN}

\section{Karakteristik Responden}

Karakteristik petani padi sawah di Kelurahan Kemumu Kecamatan Argamakmur meliputi umur, tingkat pendidikan formal, pengalaman berusahatani, jumlah tanggungan keluarga, dan luas lahan . Komposisi umur petani daerah penelitian menunjukkan bahwa persentase umur terbesar dari petani padi sawah dengan menggunakan hand traktor berada pada kelompok 
usia 38-50 tahun sebesar 40,91\% dan petani padi sawah tanpa menggunakan hand traktor sebesar 50,00 \%. Hal ini menunjukan bahwa sebagian besar petani padi sawah berada pada usia produktif.

Ditinjau dari tingkat pendidikan, mayoritas petani padi sawah dengan menggunakan hand traktor dan tanpa menggunakan hand traktor berada pada tingkat pendidikan tamat SD yaitu sebesar 45,45\%. Hal ini menunjukan tingkat pendidikan yang seperti ini dapat mempengaruhi pengetahuan dan tingkat adopsi inovasi petani terhadap teknologi pertanian yang berkaitan dengan usahatani padi sawah. Menurut Suhardjo dan Patong (1983) dalam Lamusa, A (2010) petani dengan tingkat pendidikan lebih tinggi, lebih efisien mengelola usahatani dibandingkan responden dengan tingkat pendidikan lebih rendah. Meskipun memiliki tingkat pendidikan yang rendah, petani di desa ini memeiliki pengalaman berusahatani yang cukup lama. Berdasarkan pengalaman berusahatani, petani di Kelurahan Kemumu menunjukkan rata-rata lamanya berusahatani padi sawah dengan menggunakan hand traktor sebesar $43,18 \%$ pada kategori $<15$ tahun. Pengalaman usahatani padi sawah tanpa menggunakan hand traktor sebesar 40,91 dengan kategori $>25$ tahun.

Lebh jauh, berdasarkan jumlah tanggungan keluarga antara petani padi sawah dengan menggunakan hand traktor berada sama dengan petani padi sawah tanpa menggunakan hand traktor dengan rata-rata pada kategori 2-4 orang. Berdasarkan hasil penelitian menunjukan bahwa komposisi petani berdasarkan luas lahan yang dimiliki antara petani padi sawah dengan dan tanpa menggunakan handtraktor tidak ada perbedaan yang signifikan sebab sebagian besar luas lahan yang dimiliki petani berada pada rata - rata kategori 0,44 - 0,66 ha.

\section{Penggunaan dan Biaya Sarana Produksi}

Gambaran penggunaan faktor-faktor produksi pada usahatani padi sawah di Kelurahan Kemumu Kecamatan Argamakmur Kabupaten Bengkulu Utara dapat dilihat pada Tabel 1.

\section{Penggunaan dan Biaya Benih}

Dari hasil penelitian penggunaan benih rata-rata tiap musim tanamnyapada petani pengguna hand traktorsebanyak $23,01 \mathrm{Kg} / \mathrm{Ha} / \mathrm{Mt}$ sedangkan pada petani tanpa menggunakan hand traktor sebanyak $22,73 / \mathrm{Kg} / \mathrm{Ha} / \mathrm{Mt}$. Ini berarti usahatani padi sawah dengan menggunakan hand traktor lebih banyak menggunakan benih dibandingkan usahatani padi sawah tanpa menggunakan hand traktor. Hal ini disebabkan oleh hasil pengolahan lahan dengan menggunakan hand traktor yang lebih halus dan merata yang dapat ditanami secara lebih maksimal. Perbedaan ini juga berimbas pada biaya yang harus dikorbankan oleh petani untu benih, meskipun tidak signifikan. Jumlah biaya pembelian benih yang dikeluarkan oleh petani pengguna hand traktor dibandingkan dengan petani tanpa menggunakan 
hand traktor terdapat selisih rata-rata biaya yang tidak signifikan yaitu sebesar Rp. 2.082,76/Ha/Mt. Jumlah biaya rata-rata yang dikeluarkan tiap musimnya oleh petani untuk pembelian benih tidak jauh berbeda sebab tidak adanya perbedaan secara signifikan terhadap sistem pola tanam, jarak tanam ataupun luas tanam yang diusahakan.

Tabel 1 Struktur Penggunaan Input dan Biaya Usahatani padi Sawah per HA per musim tanam

\begin{tabular}{|c|c|c|c|c|c|c|}
\hline \multirow{2}{*}{ Jenis Input } & \multicolumn{3}{|c|}{ Petani Traktor } & \multicolumn{3}{|c|}{ Petani tanpa Traktor } \\
\hline & MT 1 & MT 2 & MT 3 & MT 1 & MT 2 & MT 3 \\
\hline \multicolumn{7}{|c|}{ STRUKTUR PENGGUNAAN INPUT } \\
\hline Benih (Kg) & 22.78 & 23.12 & 23.12 & 22.73 & 22.73 & 22.73 \\
\hline Pupuk (Kg) Urea & 236.4 & 243.2 & 224.78 & 231.15 & 228.99 & 229.86 \\
\hline SP-36 & 167.24 & 184.83 & 168.69 & 167.01 & 164.43 & 173.47 \\
\hline Phonska & 236.4 & 244.49 & 226.07 & 231.15 & 228.99 & 229.86 \\
\hline Pestisida (Ltr) Marshal & 0.57 & 0.56 & 0.48 & 0.61 & 0.47 & 0.62 \\
\hline Klengset & 0.52 & 0.52 & 0.52 & 0.76 & 0.76 & 0.76 \\
\hline Herbisida & 1.11 & 1.08 & 1.11 & 1.26 & 1.12 & 1.23 \\
\hline Pospit (Kg) & 0.63 & 0 & 0 & 0.81 & 0 & 0 \\
\hline Tenaga Kerja (HKSP) & 29.3 & 25.27 & 25.87 & 44.24 & 38.63 & 39.72 \\
\hline \multicolumn{7}{|c|}{ STRUKTUR BIAYA } \\
\hline \multicolumn{7}{|l|}{ BiayaVariabel (VC) } \\
\hline Benih & $170,841.94$ & $168,799.93$ & $173,424.59$ & $170,454.55$ & $165,909.09$ & $170,454.55$ \\
\hline \multicolumn{7}{|l|}{ Pupuk } \\
\hline Urea & $425,516.53$ & $389,118.46$ & $404,597.11$ & $416,064.05$ & $366,391.18$ & $413,739.67$ \\
\hline Sp-36 & $367,935.61$ & $369,662.53$ & $387,986.40$ & $362,244.90$ & $328,856.75$ & $398,975.55$ \\
\hline Phonska & $614,634.99$ & $586,776.86$ & $565,168.73$ & $600,981.40$ & $549,586.78$ & $574,638.43$ \\
\hline \multicolumn{7}{|l|}{ Pestisida } \\
\hline Marshall & $100,740.36$ & $94,171.83$ & $81,465.22$ & $109,848.48$ & $82,343.32$ & $110,063.71$ \\
\hline Klengset & $48,768.94$ & $46,918.04$ & $47,692.84$ & $73,863.64$ & $71,280.99$ & $71,280.99$ \\
\hline Herbisida & $59,123.62$ & $57,003.27$ & $61,702.82$ & $67,820.25$ & $59,641.87$ & $69,008.26$ \\
\hline Pospit & $77,031.68$ & - & - & $99,776.17$ & - & - \\
\hline Tenaga Kerja & $3,081,017.60$ & $2,919,796.00$ & $2,943,663.90$ & $3,375,619.80$ & $3,151,489.30$ & $3,194,920.80$ \\
\hline Angkut Produksi & $295,359.85$ & $312,620.52$ & $311,163.91$ & $310,175.62$ & $326,033.06$ & $322,417.36$ \\
\hline Sewa Traktor/ ternak & $911,466.94$ & $911,466.94$ & $911,466.94$ & $870,351.24$ & $870,351.24$ & $870,351.24$ \\
\hline Jumlah Biaya Variabel & $6,152,438.06$ & $5,856,334.38$ & $5,888,332.46$ & $6,457,200.10$ & $5,971,883.58$ & $6,195,850.56$ \\
\hline \multicolumn{7}{|l|}{ Biaya Tetap } \\
\hline Pajak Lahan & 10691.29 & 10.691 .29 & 10.691 .29 & 11544.42 & 11544.42 & 11544.42 \\
\hline Penyusutan Alat & 155829.19 & 155829.19 & 155829.19 & 148201.37 & 148201.37 & 148201.37 \\
\hline Jumlah Biaya Tetap & 166520.48 & 155829.19 & 155829.19 & 159745.79 & 159745.79 & 159745.79 \\
\hline Total Biaya & $6,318,958.54$ & $6,012,163.57$ & $6,044,161.65$ & $6,616,945.89$ & $6,131,629.37$ & $6,355,596.35$ \\
\hline
\end{tabular}

Sumber: data primer diolah (2012)

\section{Penggunaan Faktor Produksi Pupuk}

Hasil penelitian menunjukkan bahwa rata-rata jumlah penggunaan pupuk antara petani padi pengguna hand traktor dengan petani tanpa menggunakan memiliki perbedaan yang tidak besar. Jumlah pupuk oleh petani pengguna traktor sebesar $644,03 \mathrm{Kg} / \mathrm{Ha} / \mathrm{MT}$, sementara petani bukan pengguna traktor menggunakan pupuk sebesar $628,30 \mathrm{Kg} / \mathrm{Ha} / \mathrm{MT}$. Artinya, petani pengguna hand traktor lebih banyak memakai pupuk sebesar 15,73

148 | Harry Tsaputra, Bambang Sumantri dan Agus Purwoko. Analisis ... 
$\mathrm{Kg} / \mathrm{Ha} / \mathrm{MT}$ daripada petani padi tanpa menggunakan hand traktor. Hal ini utamanya dipengaruhi oleh kemampuan daya beli petani terhadap kebutuhan pupuk pada usahatani padi, bukan oleh penggunaan traktor. Jenis pupuk yang digunakan terdiri dari Urea, SP-36 dan Phonska. Jika dilihat perbedaan antar musim, maka terdapat perbedaan sebesar Rp. 28.796,78/Ha/MT dan Rp. 100.723,14/Ha/MT masing - masing untuk biaya pupuk yang dikeluarkan petani dengan dan tanpa menggunakan hand traktor. Sedangkan pada musim tanam ketiga dimana jumlah biaya produksi yang dikeluarkan petani pengguna hand traktor lebih kecil dengan selisih biaya yaitu Rp. 29.601,41/Ha/MT.

\section{Penggunaan dan Biaya Pestisida}

Jenis pestisida yang digunakan adalah Marshall, klengset, Pospit, dan herbisida yang digunakan selama satu kali musim tanam. Pada tiap musim tanamnya jumlah dan biaya produksi pupuk yang dikeluarkan oleh petani pengguna hand traktor lebih kecil dibandingkan petani tanpa menggunakan hand traktor. Perbandingan jumlah penggunaan pestisida oleh petani pengguna hand traktor dengan jumlah penggunaan pestisida oleh petani tanpa menggunakan hand traktor cukup besar pada tiap musim tanamnya dengan selisih rata-rata jumlah penggunaan pestisida pada usahatani padi sebanyak 0,4 Ltr/Ha/Mt. Hal ini disebabkan oleh faktor topografi lahan dimana pada petani tanpa menggunakan hand traktor lebih besar kemungkinan mudah tersrang hama karena sumber pengairan yang didapat berasal dari lahan di atasnya yang merupakan sebagian besar lahan milik petani padi tanpa menggunakan hand traktor.

\section{Penggunaan dan Biaya Tenaga Kerja}

Berdasarkan hasil penelitian diketahui bahwa terdapat perbedaan yang signifikan terhadap jumlah rata-rata penggunaan tenaga kerja dengan jumlah selisih penggunaan tenaga kerja oleh petani tanpa menggunakan hand traktor mencapai 13,19 HKSP/Ha/MT. Angka ini menginformasikan bahwa penggunaan hand traktor mampu menurunkan penggunaan tenaga kerja rata-rata sebesar 13,19 $\mathrm{HKSP} / \mathrm{Ha} / \mathrm{Mt}$. Alasan yang dapat menjelaskan temuan ini adalah penggunaan handtractor dapat menghasilkan hasil olahan yang lebih baik dibandingkan dengan penggunaan hewan ternak seperti yang banyak digunakan oleh petani padi di daerah peneliitian ini. Hasil olehan tanah yang baik juga berimbas pada penghematan penggunaan tenaga kerja pada proses atau tahapan usahatani padi berikutnya, seperti tahap penanaman, penyiangan, dan penyulaman. Dampak penghematan penggunaan tenaga kerja adalah jumlah biaya tenaga kerja yang dikeluarkan petani pada pengguna hand traktor jauh lebih kecil dibandingkan dengan petani tanpa menggunakan hand traktor. 


\section{Biaya Angkut Produksi}

Biaya angkut produksi yang dikeluarkan petani dipengaruhi oleh jumlah produksi petani yang akan di angkut dan jarak lahan. Berdasarkan penelitian rata-rata jumlah biaya angkut tiap musim tananmnya yang dikeluarakan oleh petani pengguna hand traktor Rp. 306.381,43/Ha/MT sedangkan pada petani padi tanpa menggunakan hand traktor sebesar Rp. 319.542,01/Ha/MT dengan selisih biaya sebesar Rp. 13.160,58.

\section{Struktur Biaya Tetap}

Biaya tetap yang dikeluarkan dalam penelitian ini adalah biaya sewa alat, pajak lahan, dan penyusutan alat yang dihitung dalam satu kali musim tanam dan per hektar. Berdasarkan hasil penelitian diketahui bahwa rata rata pajak yang dikeluarkan oleh petani padi sawah pada daerah penelitian adalah 10.691,29/Ha/MT oleh petani dengan menggunakan hand traktor dan Rp. 11.544,42/Ha/MT oleh petani tanpa menggunakan hand tractor. Jumlah biaya penyusutan alat yang dikeluarkan oleh petani pengguna hand traktor sedikit lebih besar pada tiap musim tanamnya. Petani pengguna hand traktor mengeluarkan biaya penyusutan alat yaitu Rp. 7627,82/Ha/Mt lebih besar dibandingkan oleh petani tanpa menggunakan hand traktor.

\section{Produksi, Penerimaan, Pendapatan dan Efisiensi Usahatani Padi Sawah.}

Produksi usahatani padi yang dimaksud dalam penelitian ini terdiri dari jumlah padi sawah yang dihasilkan oleh petani dalam satu kali musim tanam. Penerimaan usahatani dapat diketahui dengan cara mengalikan antara jumlah produksi yang dihasilkan dengan harga jual saat petani menjual hasil produksi dalam bentuk gabah kering panen (GKP) ke penangkar atau pedagang pengumpul. Rincian rata-rata produksi, penerimaan, dan pendapatan petani padi sawah dengan dan tanpa menggunakan hand traktor selama tiga musim tanam dapat dilihat pada Tabel 2.

Hasil penelitian menemukan tidak adanya perbedaan jumlah hasil produksi padi sawah antara petani padi pengguna hand traktor dengan tanpa menggunakan hand traktor. Meskipun demikian, hasil penelitian menunjukkan terdapat perbedaan yang cukup signifikan terhadap rata - rata pendapatan yang diterima. Rata - rata pendapatan yang diterima oleh petani padi pengguna hand traktor tiap musimnya jauh lebih besar dibandingkan dengan rata-rata pendapatan yang diperoleh oleh petani tanpa menggunakan hand traktor. Jika dianalisa lebih dalam, perbedaan tampaknya lebih banyak disebabkan oleh adanya perbedaan harga yang diterima oleh petani, disamping penghematan biaya. 
Tabel 2 Rata - Rata Produksi, Penerimaan, Pendapatan dan Efisiensi Usahatani Padi Sawah

\begin{tabular}{|c|c|c|c|c|c|c|c|}
\hline \multirow{2}{*}{ MT } & \multicolumn{2}{|c|}{ Produksi $(\mathrm{kg}) / \mathrm{MT}$} & \multicolumn{2}{|c|}{ Penerimaan (Rp./MT) } & \multicolumn{2}{|c|}{ Pendapatan (Rp./MT) } & \multirow{2}{*}{$\begin{array}{l}\mathrm{R} / \mathrm{C} \\
\text { ratio }\end{array}$} \\
\hline & Per UT & Per Ha & Per UT & Per Ha & Per UT & Per Ha & \\
\hline \multicolumn{8}{|c|}{ Dengan Handtractor } \\
\hline I & $2.685,23$ & $5.060,69$ & $9.501 .590,91$ & $17.815 .082,64$ & $6.167 .114,38$ & $11.496 .124,15$ & 2,84 \\
\hline II & $2.876,14$ & $5.381,37$ & $10.468 .522,73$ & $19.489 .325,07$ & $7.583 .225,74$ & $13.466 .470,22$ & 3,26 \\
\hline III & $2.852,27$ & $5.349,78$ & $9.525 .454,55$ & $17.769 .507,58$ & $6.618 .578,01$ & $11.714 .654,62$ & 2,95 \\
\hline \multicolumn{8}{|c|}{ Tanpa Handtractor } \\
\hline I & $2.359,09$ & $4.838,15$ & $8.177 .272,73$ & $16.659 .090,91$ & $5.215 .896,74$ & $10.036 .965,64$ & 2,53 \\
\hline II & $2.465,91$ & $5.092,11$ & $8.791 .590,91$ & $18.038 .137,05$ & $6.066 .339,92$ & $11.906 .507,65$ & 2,95 \\
\hline III & $2.436,36$ & $5.030,13$ & $7.954 .545,46$ & $16.309 .056,47$ & 4.897.442,19 & $9.953 .460,13$ & 2,58 \\
\hline
\end{tabular}

Sumber : Data Primer diolah, 2012

Keterangan:

- Harga Gabah yang diterima petani tractor: MT I : Rp. 3.522,73/Kg, MT II: Rp. 3.622,73/Kg, dan MT : Rp. 3.322,73/Kg

- Harga Gabah yang diterima petani tanpa tractor MT I: Rp. $3.445,46 / \mathrm{Kg}$, MT II : Rp. $3.545,46 / \mathrm{Kg}$, dan MT III $\quad$ : Rp. $3.245,46 / \mathrm{Kg}$

Nilai $\mathrm{R} / \mathrm{C}$ ratio usahatani padi sawah dengan menggunakan hand traktor pada setiap musim tanamnya sebesar 3,02, sedangkan usahatani padi sawah tanpa menggunakan hand traktor sebesar 2,69. Nilai R/C ratio usahatani padi sawah dengan dan tanpa menggunakan hand traktor yang nilainya lebih besar dari 1 menunjukan bahwa usahatani sudah memberikan keuntungan bagi petani. Hasil ini lebih besar jika dibandingkan dengan temuan Syafiri (2004). Syafiri menemukan bahwa tingkat efisiensi usahatani padi sawah petani pengguna hand traktor di Desa Pasar Pino Kecamatan Pino Raya Kabupaten Bengkulu Selatan sebesar 1,80 dan t tanpa menggunakan hand traktor sebesar 1,51. Lebih lanjut, berdasarkan hasil perhitungan uji beda rata-rata, secara statistik nilai $t_{\text {hitung }} \geq t_{\text {tabel. }}$. Hasil ini menjelaskanbahwa terdapat perbedaan tingkat efisiensi yang signifikan pada usahatani padi sawah dengan dan tanpa menggunakan hand traktor pada taraf kepercayaan 95\%. Hal yang sama juga ditemukan dalam penelitian Sriyoto, dkk (2009), yang menyimpulkan usahatani padi yang dilakukan oleh petani di Provinsi Bengkulu pada dua tipologi lahan yang berbeda.

\section{SIMPULAN DAN SARAN}

\section{Simpulan}

Berdasarkan hasil penelitian dan analisis yang dilakukan maka dapat diambil kesimpulan bahwa usahatani yang diusahakan oleh petani dengan menggunakan handtractor ataupun tidak adalah efisien. Namun, tingkat efisiensi 
usahatani padi petani penggguna handtractor lebih tinggi. Hal ini ditunjukkan oleh nilai rata-rata $\mathrm{R} / \mathrm{C}$ ratio pada usahatani padi sawah dengan menggunakan hand traktor sebesar 3,02 dibandingkan 2,69 pada usahatani padi sawah tanpa menggunakan tractor.

\section{Saran}

Untuk dapat lebih dapat meningkatkan efisiensi penggunaan hand tractor perlu dibangun usahatani agar hand traktor dapat di aplikasikan pada topografi lahan yang bertingkat. Hal ini akan dapat mempercepat pengolahan lahan dan meningkatkan efisiensi penggunaantenaga kerja.

\section{DAFTAR PUSTAKA}

Badan Pusat Statistik. 2010. Provinsi Bengkulu Dalam Angka 2010. Bengkulu. Soekartawi, 1995. Analisa Usahatani. UI-Press, Jakarta.

Syafiri, M. 2004. Analisis Usahatani Padi Sawah Pada Petani Pengguna Hand Traktor dan Non Pengguna Di Desa Pasar Pino Kecamatan Pino Raya Kabupaten Bengkulu Selatan. Skripsi. Jurusan Sosial Ekonomi Pertanian, Fakultas Pertanian, Universitas Bengkulu (tidak dipublikasikan).

Sriyoto, Winda Herveny, dan Ketut Sukiyono. 2009. Efisiensi Ekonomi Usahatani Padi Pada Dua Tipologi Lahan Yang Berbeda Di Propinsi Bengkulu Dan Faktor-Faktor Determinannya. Jurnal Akta Agrosia. Edisi Khusus No. 2: 155 - 163. 